\title{
RUSSIAN INDUSTRY IN SEPTEMBER 2015
}

\author{
S.Tsukhlo
}

First September data obtained from the Gaidar Institute business surveys ${ }^{1}$ has demonstrated high adjustment of Russian industry to 2015 recession pattern. Sluggish negative demand dynamic suits the majority of enterprises and allows them to steadily control finished products' stocks. Output growth registered by the September survey looks like a random upsurge on the relatively smooth surface of the current recession and is not buttressed by the revision of plans and projections of enterprises.

\section{Demand for industrial products}

In September, demand dynamic did not undergo any major changes regarding neither initial nor seasonally adjusted data (Fig.1). Both balances preserve moderate negative values which are worse than in 2014 but obviously better than were in classically crisis 2009. The same outlook is observed regarding projections of enterprises. This indicator began conventional and by far non recession decline by the end of the year which is usually observed during this period.

As a result, current demand volumes received "high" estimates by the Russian producers. Over half of enterprises (59\% in August and 58\% in September) estimated their actual sales volumes as "normal". This is the best result obtain during 2015. It barely differs from the pre-crisis maximum of $61 \%$ (AugustSeptember 2014) and inter-crisis peak of $64 \%$ registered in October 2011. The industry, thus, demonstrates high adaptability to the slow rolling 2015 recession.

\section{Stocks of finished goods}

The same conclusions can be made out of the analysis of estimates of stocks of finished goods which enterprises provide according to the scale "above norm", "normal" and "below norm" (Fig. 2). Principal crisis indicator, a share of responses "above norm", demonstrates in 2015 a surprising stability and anything but crisis level. Firstly, in the course of nine months of 2015, this indicator remains in the range of $11-15 \%$ and during recent four months posts the same value $-14 \%$. Secondly, obtained during 2015 values represent nearly an absolute minimum for the 23-year history of this indicator monitoring. Thus, for the umpteenth time the industry demonstrates by far not crisis

1 Business surveys of managers of industrial enterprises have been conducted by the Gaidar Institute using a European harmonized method in monthly cycles since September 1992, covering the entire territory of the Russian Federation. The panel size is about 1,100 enterprises employing over $15 \%$ of industrial employees. The panel is shifted towards large enterprises for each of the segregated sub-industries. The ratio of returned questionnaires is $65-70 \%$.

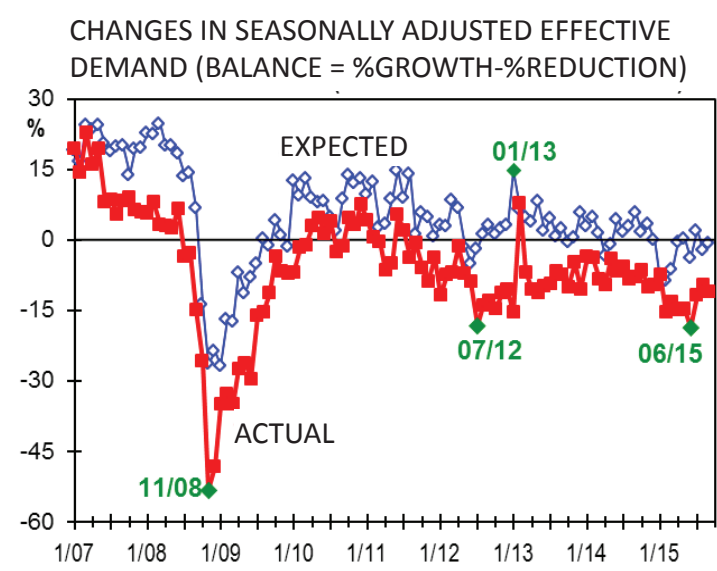

Fig. 1

DYNAMICS OF ESTIMATED STOCKS OF FINISHED GOODS, \%

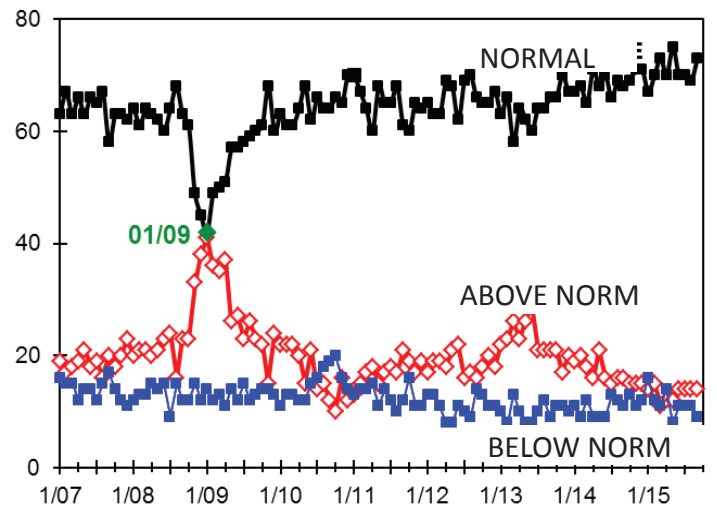

Fig. 2

estimates of stocks of finished goods. Adaptation of enterprises to the current marketing conditions which is share of responses "normal", on the contrary, in 2015 has reached its all-time high.

\section{Output}

Following prolonged slow rolling recession of the first eight months of 2015, in September, the industry, perhaps, has taken a risk and has revised its most cautious practice of determining output volumes. In September 2015, survey indicator of the actual out- 
put has demonstrated a drastic and positive change of balance (growth rate) by 14 points on initial data and by 10 points on seasonally adjusted data (Fig. 3). Consequently, both indicator became positive, i.e. they have demonstrated production growth against august 2015. Will this result signify recovery of the Russian industry out of the prolonged recession is quite premature to speculate. Firstly, these changes have to take a sustainable character and not be limited to a few months. Secondly, official projections should serve as a reliable roadmap for enterprises but not misinform them. Thirdly, proper enterprises should believe in sustainable output growth. The latter can be analyzed across production plans of enterprises.

In 2015, this seasonally adjusted indicator does not cross the limits of its values posted in 2012-2014. Even panic characteristic of Q1 2015 failed to reduce it to a pre (crisis) level. However, values of the recent months do not provide impression that that the enterprises are going to bounce back. They remain on the same by far not (post) crisis limits. Thus, while the Russian industry does not have grounds for transition to a positive and sustainable output dynamic.

\section{Investment plans of enterprises}

In this situation, high investment pessimism of the Russian enterprises registered in Q3 2015 looks absolutely justifiable. Balance of the investment pans in production remains significantly negative (-17 points in the pasted quarter). Although, it looks not so pessimistic as at the turn of the year when industry succumbing to a general panic reduced its plans to -29 points which is the lowest value of the indicator for five years (Fig. 4). In the meantime, actual (reduced by $6 \%$ against the same period last year) investment volumes of Q1 2015 have satisfied solely $43 \%$ of enterprises (also fiveyear minimum. To be true, monitoring of this indicator commenced solely from Q2 2010). Judging by the volume of investment, Q2 and Q3 2015 have already become better: $54 \%$ and $\% 52$, respectively under the same scale of their volumes reduction. Thus, industry demonstrates adjustment to 2015 recession along this indicator.

Meanwhile, depreciation of the national currency and appreciation of foreign equipment have become a strong discouraging factor of the investment activity of the Russian industry. If in January 2014, price reduction of equipment and SMR could contribute to the investment into production of $41 \%$ of enterprises, then by June 2015 the need to reduce these prices went up by $55 \%$. Investment import substitution feasibility for the Russian economy is now limited, firstly, due to lack of manufacture in the territory of the country of a considerable part of locally made equipment.

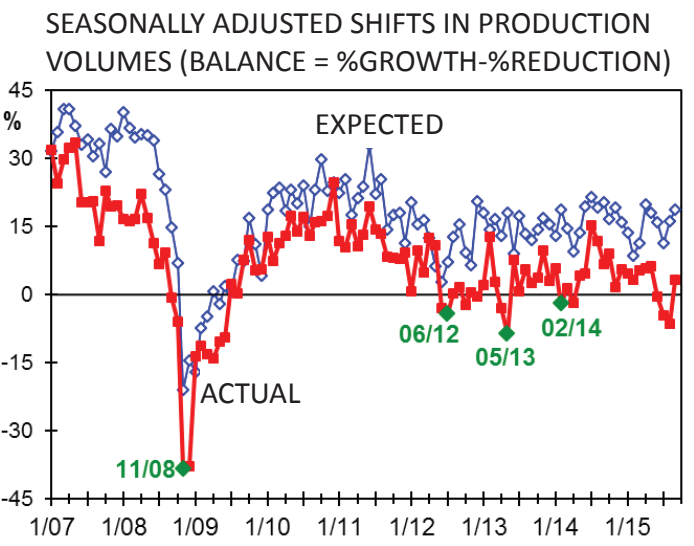

Fig. 3

BALANCE OF EXPECTED INVESTMENT AND SATISFACTION OF THE ACTUAL VOLUMES

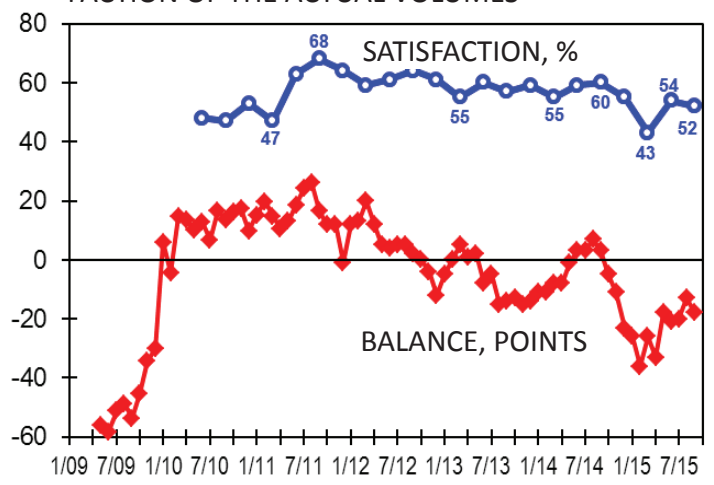

Fig. 4

CHANGES IN PRICE OF GOODS LEAVING FACTORY GATE (BALANCE - \%GROWTH-\%REDUCTION)

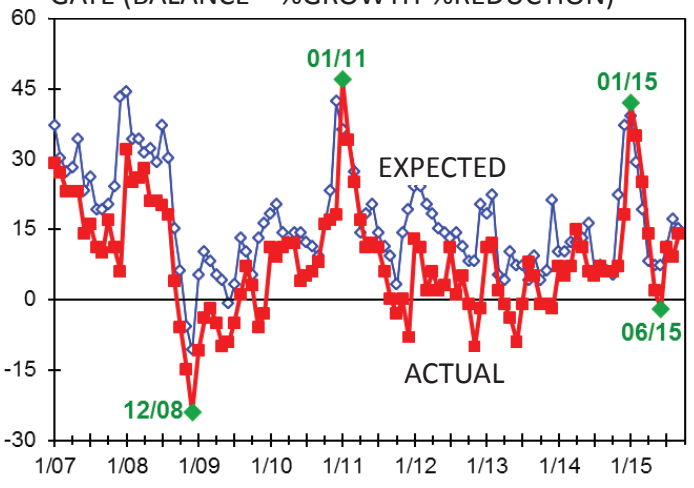

Fig. 5

\section{Business pricing policy}

September data has demonstrated that the August slowdown of the price growth of goods leaving factory stopped. The balance (growth rate) of the indicator up 5 points and the growth against June which was the lowest bottom in 2015 has already constituted 16 points (Fig. 5). To note, H1 2015 was characterized by a constant reduction of the indicator which resulted in the fall of the indicator from +42 to -2 points. Forecasts of price change have remained in September practically at the August level (record high for Q2-Q3 2015). 